\title{
Obesity and overweight prevalences in rural and urban populations in East Spain and its association with undiagnosed hypertension and Diabetes Mellitus: a cross-sectional population-based survey
}

\author{
Antonio Hernández-Mijares 1,2,3, Eva Solá-Izquierdo1,2, Francisco Ballester- \\ Mechó $^{4}$, María Teresa Marí-Herrero5 ${ }^{5}$ Juan Vicente Gilabert-Molés ${ }^{4}$ \\ Natalia Gimeno-Clemente ${ }^{3,6}$ and María Morales-Suárez-Varela*3,6,7
}

\begin{abstract}
Address: ${ }^{1}$ Service of Endocrinology, University Hospital Dr. Peset, Valencia, Spain, ${ }^{2}$ Department of Medicine, University of Valencia, Valencia, Spain, ${ }^{3}$ Research group CIBER CB06/02/0045, CIBER actions - Epidemiology and Public Health. Health Institute Carlos III, Madrid, Spain, ${ }^{4}$ Official College of Pharmacists of Castellón, Spain, ${ }^{5}$ Diabetes Unit of Hospital de la Plana, Castellón, Spain, ${ }^{6}$ Unit of Public Health. Department of Preventive Medicine, University of Valencia, Spain and ${ }^{7}$ Foundation for Investigation. University Hospital Dr. Peset, Valencia, Spain

Email: Antonio Hernández-Mijares - hernandez_antmij@gva.es; Eva Solá-Izquierdo - eva.sola@uv.es; Francisco Ballester-

Mechó - cofcastellon@redfarma.org; María Teresa Marí-Herrero - mari_mar@gva.es; Juan Vicente Gilabert-Molés - cofcastellon@redfarma.org; Natalia Gimeno-Clemente - nataliaclemente82@hotmail.com; María Morales-Suárez-Varela* - maria.m.morales@uv.es

* Corresponding author
\end{abstract}

Published: 27 July 2009

BMC Research Notes 2009, 2:151 doi:10.1/86/1756-0500-2-15
Received: 18 February 2009

Accepted: 27 July 2009

This article is available from: http://www.biomedcentral.com/I756-0500/2/I5I

(C) 2009 Morales-Suárez-Varela et al; licensee BioMed Central Ltd.

This is an Open Access article distributed under the terms of the Creative Commons Attribution License (http://creativecommons.org/licenses/by/2.0), which permits unrestricted use, distribution, and reproduction in any medium, provided the original work is properly cited.

\begin{abstract}
Background: An increase in the number of overweight and obese subjects in the general population has been observed.

The aim of this study was to determine the prevalence of overweight and obese subjects in the general population and its association with undiagnosed pathologies, such as diabetes mellitus [DM] and hypertension $[\mathrm{HT}]$, by taking age, gender and place of residence [rural or urban] into account.

Findings: A cross-sectional population-based survey was conducted in Castellón, East Spain in 2005-2006. The sample included 2,062 participants aged 18-94 years. Weight, height, blood pressure and glycaemia values were recorded, and information about gender, age and place of residence was obtained. Overweight, obesity, and undiagnosed HT and DM prevalences were calculated. Multiple regression analyses were done to assess the association of overweight/obesity with undiagnosed HT and DM by adjusting for age, gender and place of residence.

The overall overweight, obesity, and undiagnosed HT and DM prevalences were $39.9 \%$ [95\% Cl:37.3-42.0], 25.9\% [95\% Cl:24.0-27.9], 9.0\% [95\% Cl:7.8-10.4] and 12.6\% [95\% Cl:II.2-I4.I], respectively. We identified various independent risk factors; those relating to overweight were increasing age, male gender and rural residential area, while that relating to obesity was increasing age. Compared to normal weight adults, the Relative Prevalence Ratio (RPR) for subjects who were overweight and had HT was 2.00 [95\% Cl:I.2I-3.32]; that for obesity and HT was 1.91 [95\% Cl:I.48-2.46], and it was I.50 [95\% Cl:1.25-I.8I] for obesity and DM.

Conclusion: Overweight and obesity prevalences, and their association with undiagnosed DM and $\mathrm{HT}$, are high in our study population.
\end{abstract}




\section{Background}

In the last two decades, the prevalence of overweight and obesity has increased worldwide [1], mainly in the adult population [2], and in both developed and developing countries [3].

In Europe, obesity prevalence rates have increased by $30 \%$ since the mid 80's [4], and are presently between 4.0$28.3 \%$ in men, and 6.2-36.5\% in women. Diverse findings have been noted among various European countries: Eastern and Mediterranean countries have the highest prevalence, and Western and Northern countries have the lowest [4].

It is suspected that Spain has the highest prevalences in the European Union for both genders [4], and a geographical prevalence distribution also exists within Spain, this being higher in Southeast and Northern Spain [5,6]. A growing trend, which is in line with the rest of the world, is also noted and will imply increased associated mortality and, indeed, currently claims some 28,000 deaths a year $[6,7]$.

This increased prevalence of obesity has also been associated with the increased risk of numerous comorbidities like hypertension [HT] [8-10] and diabetes mellitus [DM] $[10,11]$. A linear relationship between adiposity and HT has been noted [12]. Diabetes mellitus is a world public health priority, not only because its prevalence has sharply increased in the last decade [10], but also because of the high morbidity and mortality that it causes $[13,14]$.

This study aims to determine the overweight and obesity prevalences in the general adult population and their association with undiagnosed pathologies [DM and HT] by taking age, gender and area of residence [rural or urban] into account.

\section{Methods}

\section{Study design}

A cross-sectional study was done in a general population of Castellón, Eastern Spain in 2005-2006.

\section{The study population}

The study population included subjects aged 18 years or older and who were undiagnosed with DM and HT.

In the study area [Castellón], there are 3 Health Districts with a population of 431,093 subjects aged 18 years or older [15].

Of this population we selected 8,400 subjects by a random, stratified, multi-stage sampling technique in which the first-stage units were Primary Health Care Centres. Those with diagnosed HT or/and DM were excluded $[3,503,41.7 \%]$.
The other 4,898 subjects [undiagnosed of HT and DM] were located by telephone and invited to participate in the study. This sample size allows us an accuracy of $99.0 \%$ for an expected obesity prevalence of $15.5 \%$ [3]. The subjects who accepted invitations to participate were seen in a centre of biological analysis.

The final sample included 2,062 adults [response rate, $42.1 \%$ ], 643 men [31.18\%] and 1419 women [68.82\%]. This sample size allows us to an accuracy of $98.5 \%$ for an expected obesity prevalence of $15.5 \%$ [3].

Participants' ages ranged from 18 to 94 years. The mean age of men and women was $58.00 \pm 14.73$ and $54.83 \pm$ 14.52 respectively. Written consent to participate in the study was obtained from all the participants.

\section{Measurements}

Specially trained professionals [clinical specialist pharmacists] conducted an anthropometric study with the participants. This study recorded weight $[\mathrm{kg}]$, height, and calculated body mass index [BMI] $\left[\mathrm{kg} / \mathrm{m}^{2}\right]$. Those individuals whose BMI was between 25.0 and $29.9 \mathrm{~kg} / \mathrm{m}^{2}$ were considered overweight, while those with a BMI equal or over $30 \mathrm{~kg} / \mathrm{m}^{2}$ were classified as obese [7].

The participants' blood pressure was consecutively taken three times and the arithmetic mean was calculated. Diagnosing HT was conducted by following the World Health Organization's [WHO] criteria [HT: subjects with systolic pressure > $140 \mathrm{mmHg}$, and diastolic pressure > 90 $\mathrm{mmHg}$ [8].

Capillary glycaemia [CG] was also determined in all the participants. Only in those participants whose CG value exceeded $106 \mathrm{mg} / \mathrm{dl}$ [if he/she had not eaten breakfast] or $140 \mathrm{mg} / \mathrm{dl}$ [if he/she had eaten breakfast], was venous glycaemia [VG] also dertmined by taking blood samples [before they ate breakfast in all the cases]. Diagnosing DM was conducted based on VG by following the American Diabetes Association criteria [DM: subjects with a VG value before eating breakfast of $>126 \mathrm{~g} / \mathrm{dl}$ ] [16].

Information about the participants' age, gender, and place of residence was obtained through interviews. We distinguished between places of residence as follows: rural areas with $<10,000$ inhabitants; urban: areas with $\geq 10,000$ inhabitants.

\section{Statistical analysis}

Overweight, obesity and undiagnosed HT and DM [who were not on HT/DM treatment and whose blood pressure/ VG exceeded the limits stated] prevalences were calculated with their corresponding confidence intervals [CI 95\%]. Comparisons were done with the Chi-square test [p $\leq$ 0.05]. 
Given the sample's lack of representativeness, prevalences were estimated in the adult population of the province of Castellón by the direct standardisation procedure for samples in terms of age and gender [17] by taking the 2008 population census as a reference [15].

In order to determine the relationship of being overweight/obese with age, gender, place of residence and having undiagnosed $\mathrm{DM} / \mathrm{HT}$, a multiple regression logistic analysis was done by calculating the relative prevalence ratios [RPR], which was adjusted for age, gender and place of residence, as well as their corresponding CI 95\%. Statistical analyses were done with the SPSS v.15 software.

\section{Results}

\section{Overweight and obesity prevalences}

The total overweight and obesity prevalences obtained were $39.9 \%$ [95\% CI:37.7-42.0] and 25.9\% [95\% CI:24.0-27.9], respectively. By extrapolating to the adult population of Castellón, which had been adjusted for age and gender, the estimated overweight and obesity preva- lences were $38.0 \%$ [95\% CI:37.8-38.2] and $16.7 \%$ [95\% CI:16.6-16.9] [Table 1].

\section{Undiagnosed HT Prevalence}

Of all the participants, 186 had undiagnosed HT with a prevalence of $9.0 \%$ [95\% CI:7.8-10.4]. By extrapolating to the adult population of Castellón, the estimated HT prevalence was 5.5\% [95\% CI:5.4-5.6] [Table 2].

\section{Undiagnosed DM Prevalence}

Of all the participants, 260 had DM with a prevalence of $12.6 \%$ [95\% CI:11.2-14.1]. By extrapolating to the adult population of Castellón, the estimated DM prevalence was 7.3\% [95\% CI:7.2-7.4] [Table 2].

\section{Gender, age and place of residence}

As Table 1 shows, we saw a trend of the overweight prevalence increasing with age, which went from $27.4 \%$ in the 34 year-old and younger age group to $44.2 \%$ in the $45-54$ year-old age group [p-value $<0.001]$.

Table I: Age and gender stratified overweight and obesity prevalences among 2062 residents of Castellón.

\begin{tabular}{|c|c|c|c|c|c|c|}
\hline & \multicolumn{2}{|c|}{ Men } & \multicolumn{2}{|c|}{ Women } & \multicolumn{2}{|c|}{ Total } \\
\hline & Overweight & Obesity & Overweight & Obesity & Overweight & Obesity \\
\hline Age Group & $\begin{array}{c}\mathrm{No} \\
\%(95 \% \mathrm{Cl})\end{array}$ & $\begin{array}{c}\text { No } \\
\%(95 \% \mathrm{Cl})\end{array}$ & $\begin{array}{c}\text { No } \\
\%(95 \% \mathrm{Cl})\end{array}$ & $\begin{array}{c}\mathrm{No} \\
\%(95 \% \mathrm{Cl})\end{array}$ & $\begin{array}{c}\mathrm{No} \\
\%(95 \% \mathrm{Cl})\end{array}$ & $\begin{array}{c}\text { No } \\
\%(95 \% \mathrm{Cl})\end{array}$ \\
\hline$\leq 34$ & $\begin{array}{c}15 \\
39.5(25.0-55.5)\end{array}$ & $\begin{array}{c}3 \\
7.9(2.0-20.0)\end{array}$ & $\begin{array}{c}19 \\
22.0(14.3-31.8)\end{array}$ & $\begin{array}{c}4 \\
4.6(1.5-10.8)\end{array}$ & $\begin{array}{c}34 \\
27.4(20.1-35.8)\end{array}$ & $\begin{array}{c}7 \\
5.7(2.5-10.8)\end{array}$ \\
\hline $35-44$ & $\begin{array}{c}45 \\
51.2(40.7-61.5)\end{array}$ & $\begin{array}{c}16 \\
18.2(|1 .|-27.3)\end{array}$ & $\begin{array}{c}73 \\
23.8(19.3-28.8)\end{array}$ & $\begin{array}{c}42 \\
13.7(10.2-17.9)\end{array}$ & $\begin{array}{c}118 \\
29.9(25.5-34.5)\end{array}$ & $\begin{array}{c}58 \\
14.7(\mid 1.4-18.4)\end{array}$ \\
\hline $45-54$ & $\begin{array}{c}82 \\
63.0(54.5-71.0)\end{array}$ & $\begin{array}{c}22 \\
16.9(\mid 1.2-24.1)\end{array}$ & $\begin{array}{c}122 \\
36.5(3.5-41.8)\end{array}$ & $\begin{array}{c}78 \\
23.3(19.0-28.1)\end{array}$ & $\begin{array}{c}205 \\
44.2(39.7-48.7)\end{array}$ & $\begin{array}{c}100 \\
21.5(18.0-25.5)\end{array}$ \\
\hline $55-64$ & $\begin{array}{c}63 \\
46.6(38.4-55.1)\end{array}$ & $\begin{array}{c}43 \\
31.8(24.4-40.1)\end{array}$ & $\begin{array}{c}112 \\
40.6(34.9-46.5)\end{array}$ & $\begin{array}{c}100 \\
36.2(30.7-42.0)\end{array}$ & $\begin{array}{c}175 \\
42.6(37.9-47.4)\end{array}$ & $\begin{array}{c}143 \\
34.8(30.3-39.5)\end{array}$ \\
\hline$\geq 65$ & $\begin{array}{c}119 \\
47.2(41.1-53.4)\end{array}$ & $\begin{array}{c}69 \\
27.4(22.1-33.1)\end{array}$ & $\begin{array}{c}170 \\
40.9(36.2-45.6)\end{array}$ & $\begin{array}{c}157 \\
37.7(33.2-42.5)\end{array}$ & $\begin{array}{c}290 \\
43.4(39.7-47.2)\end{array}$ & $\begin{array}{c}226 \\
33.9(30.3-37.5)\end{array}$ \\
\hline
\end{tabular}

\begin{tabular}{ccccccc}
\hline Total & 324 & 153 & 496 & 381 & 822 & 534 \\
& $50.4(46.5-54.2)$ & $23.8(20.6-27.3)$ & $34.9(32.5-37.5)$ & $26.8(24.6-29.2)$ & $39.9(37.7-42.0)$ & $25.9(24.0-27.9)$
\end{tabular}

Age and gender-adjustedt \% $\quad 46.8(46.6-47.1) \quad 16.0(15.8-16.2) \quad 29.3(29.1-29.6) \quad 17.4(17.3-17.6) \quad 38.0(37.8-38.2) \quad 16.7(16.6-16.9)$ $(95 \% \mathrm{Cl})$ 
Table 2: Age and gender stratified undiagnosed hypertension and diabetes mellitus prevalences among 2062 adult residents of Castellón.

\begin{tabular}{|c|c|c|c|c|c|c|}
\hline & \multicolumn{3}{|c|}{ Hypertension } & \multicolumn{3}{|c|}{ Diabetes } \\
\hline & Men & Women & Total & Men & Women & Total \\
\hline Age Group & $\begin{array}{c}\text { No } \\
\%(95 \% \mathrm{Cl})\end{array}$ & $\begin{array}{c}\text { No } \\
\%(95 \% \mathrm{Cl})\end{array}$ & $\begin{array}{c}\text { No } \\
\%(95 \% \mathrm{Cl})\end{array}$ & $\begin{array}{c}\text { No } \\
\%(95 \% \mathrm{Cl})\end{array}$ & $\begin{array}{c}\text { No } \\
\%(95 \% \mathrm{Cl})\end{array}$ & $\begin{array}{c}\text { No } \\
\%(95 \% \mathrm{Cl})\end{array}$ \\
\hline$\leq 34$ & $\begin{array}{l}0 \\
-\end{array}$ & $\begin{array}{c}\mathrm{I} \\
1.2(0.1-5.6)\end{array}$ & $\begin{array}{c}1 \\
0.8(0.1-3.9)\end{array}$ & $\begin{array}{l}0 \\
-\end{array}$ & $\begin{array}{c}2 \\
2.3(0.4-7.5)\end{array}$ & $\begin{array}{c}2 \\
1.6(0.3-5.2)\end{array}$ \\
\hline $35-44$ & $\begin{array}{c}7 \\
7.9(3.5-15.1)\end{array}$ & $2.9 \stackrel{9}{(1.4-5.3)}$ & $\begin{array}{c}16 \\
4.0(2.4-6.4)\end{array}$ & $\begin{array}{c}3 \\
3.4(0.9-9.0)\end{array}$ & $\begin{array}{c}10 \\
3.2(1.7-5.7)\end{array}$ & $\begin{array}{c}13 \\
3.3(1.8-5.4)\end{array}$ \\
\hline $45-54$ & $\begin{array}{c}14 \\
10.7(6.3-17.0)\end{array}$ & $\begin{array}{c}26 \\
7.8(5.3-11.0)\end{array}$ & $\begin{array}{c}40 \\
8.6(6.3-11.4)\end{array}$ & $\begin{array}{c}14 \\
10.8(6.3-17.0)\end{array}$ & $\begin{array}{c}27 \\
8.0(5.5-11.4)\end{array}$ & $\begin{array}{c}41 \\
8.8(6.5-11.7)\end{array}$ \\
\hline $55-64$ & $\begin{array}{c}21 \\
15.5(10.2-22.4)\end{array}$ & $\begin{array}{c}33 \\
11.9(8.5-16.2)\end{array}$ & $\begin{array}{c}54 \\
13.1(10.1-16.7)\end{array}$ & $\begin{array}{c}29 \\
21.5(15.2-29.0)\end{array}$ & $\begin{array}{c}35 \\
12.7(9.1-17.0)\end{array}$ & $\begin{array}{c}64 \\
15.6(12.3-19.3)\end{array}$ \\
\hline$\geq 65$ & $\begin{array}{c}30 \\
11.9(8.3-16.3)\end{array}$ & $\begin{array}{c}45 \\
10.8(8.1-14.1)\end{array}$ & $\begin{array}{c}75 \\
11.2(9.0-17.8)\end{array}$ & $\begin{array}{c}60 \\
23.8(18.9-29.4)\end{array}$ & $\begin{array}{c}80 \\
19.2(15.7-23.2)\end{array}$ & $\begin{array}{c}140 \\
20.9(18.0-24.2)\end{array}$ \\
\hline Total & $\begin{array}{c}72 \\
\mid 1.2(8.9-13.9)\end{array}$ & $\begin{array}{c}114 \\
8.0(6.7-9.6)\end{array}$ & $\begin{array}{c}186 \\
9.0(7.8-10.4)\end{array}$ & $\begin{array}{c}106 \\
16.5(13.7-19.6)\end{array}$ & $\begin{array}{c}154 \\
10.8(9.3-12.6)\end{array}$ & $\begin{array}{c}260 \\
12.6(11.2-14.1)\end{array}$ \\
\hline $\begin{array}{l}\text { Age and gender-adjusted } \dagger \% \\
(95 \% \mathrm{Cl})\end{array}$ & $6.0(5.8-6.1)$ & $5.1(4.9-5.2)$ & $5.5(5.4-5.6)$ & $7.3(7.2-7.5)$ & $7.2(7.1-7.3)$ & $7.3(7.2-7.4)$ \\
\hline
\end{tabular}

Hypertension: Subjects with systolic pressure $>140 \mathrm{mmHg}$ and diastolic pressure $>90 \mathrm{mmHg}$

Diabetes: Subjects with venous glycaemia before breakfast $>126 \mathrm{~g} / \mathrm{dl}$

No $=$ Number of adults with hypertension or diabetes

† Adjusted for the age and gender distribution of the population of Castellón

Regarding the obesity prevalence, we observed that it increased with age, and went from $5.7 \%$ in the 34 year-old and younger age group to $34.8 \%$ in the 55-64 year-old age group [p-value $<0.001]$.

Table 3 shows an RPR of overweight in subjects in the 65 and older age group of 4.42 [95\% CI:2.78-7.01] compared with those subjects of younger age group [34 years and below] after adjusting for gender and place of residence. For obesity, we found an RPR of 8.75 [95\% CI:4.00-19.14] in subjects of 65 year and older compared to the younger subjects.

The overall overweight and obesity prevalences for men were $50.4 \%$ [95\% CI:46.5-54.2] and 23.8\% [95\% CI:20.6-27.3], and 34.9\% [95\% CI:32.5-37.5] and 26.8\% [95\% CI:24.6-29.2] for women. By extrapolating to the adult population of Castellón, the estimated overweight and obesity prevalences for men were 46.8\% [95\% CI:46.6-47.1] and 16.0\% [95\% CI:15.8-16.2], and 29.3\% [95\% CI:29.1-29.6] and 17.4\% [95\% CI:17.3-
17.6] for women. Men of all ages tended to have higher prevalence of overweight than women. The prevalence of obesity tended to be higher in women after age 45 years and the difference was significantly higher in the oldest age group [Table 1].

After adjusting for gender and age, we observed a high overweight prevalence among the subjects living in a rural area [p-value < 0.001] with an RPR of 1.57 [95\% CI:1.192.07] compared with those living in an urban area. For obesity, the prevalence was somewhat higher for subjects living in a rural area than for those living in an urban area, although no statistically significant differences were found [RPR of 1.31, 95\% CI:0.96-1.80] [Table 3].

Table 2 shows that the undiagnosed HT prevalence increased with age from $0.8 \%$ in the 34 year-old and younger age group and to $13.1 \%$ by age $55-64$ years. The undiagnosed DM prevalence increased with age from $1.6 \%$ in the 34 year-old and younger age group to $20.9 \%$ in the 65 year-old and older age group. 
Table 3: Overweight and obesity prevalences and adjusted effects of potential risk factors in adults.

\begin{tabular}{|c|c|c|c|c|c|c|c|c|}
\hline \multirow[b]{2}{*}{ Risk factor } & \multicolumn{4}{|c|}{ Overweight } & \multicolumn{4}{|c|}{ Obesity } \\
\hline & $\begin{array}{l}\text { Prevalence } \\
(\%)\end{array}$ & RPR & $95 \% \mathrm{Cl}$ & P-value & $\begin{array}{c}\text { Prevalence } \\
(\%)\end{array}$ & RPR & $95 \% \mathrm{Cl}$ & P-value \\
\hline \multicolumn{9}{|l|}{ Age } \\
\hline$\leq 34$ & 27.4 & I (ref.) & - & & 5.7 & I (ref.) & - & \\
\hline $35-44$ & 29.9 & 1.40 & $0.87-2.26$ & & 14.7 & 2.89 & I.28-6.54 & \\
\hline $45-54$ & 44.2 & 4.51 & $2.76-7.39$ & $<0.001$ & 21.5 & 4.55 & $2.05-10.10$ & $<0.001$ \\
\hline $55-64$ & 42.6 & 3.29 & $2.06-5.24$ & & 34.8 & 8.89 & $4.02-19.65$ & \\
\hline$\geq 65$ & 43.4 & 4.42 & $2.78-7.01$ & & 33.9 & 8.75 & $4.00-19.14$ & \\
\hline \multicolumn{9}{|l|}{ Gender } \\
\hline Woment & 34.9 & I (ref.) & - & & 26.8 & I (ref.) & - & \\
\hline Men & 50.4 & 2.06 & $1.62-2.63$ & $<0.001$ & 23.8 & 1.10 & $0.82-1.47$ & NS \\
\hline \multicolumn{9}{|l|}{ Area } \\
\hline Urbant & 38.3 & I (ref.) & - & & 26.2 & I (ref.) & - & \\
\hline Rural & 46.6 & 1.57 & I.19-2.07 & $<0.001$ & 27.8 & 1.31 & $0.96-1.80$ & NS \\
\hline
\end{tabular}

Overweight: Subjects with BMI $=25.0-29.9 \mathrm{Kg} / \mathrm{m}^{2}$

Obesity: Subjects with BMI $\geq 30.0 \mathrm{Kg} / \mathrm{m}^{2}$

RPR: Relative Prevalence Ratio adjusted for age, gender and place of residence

† Referent group

P-value based on Pearson's chi-square test

NS $=$ Non-Significant

Table 4: Undiagnosed hypertension and diabetes mellitus prevalences and adjusted effects of overweight and obesity on adults.

\begin{tabular}{|c|c|c|c|c|c|c|c|c|}
\hline \multirow[b]{2}{*}{ Risk factor } & \multicolumn{4}{|c|}{ Hypertension } & \multicolumn{4}{|c|}{ Diabetes } \\
\hline & $\begin{array}{l}\text { Prevalence } \\
\text { (\%) }\end{array}$ & RPR & $95 \% \mathrm{Cl}$ & $\mathrm{P}$-value & $\begin{array}{c}\text { Prevalence } \\
\text { (\%) }\end{array}$ & RPR & $95 \% \mathrm{Cl}$ & P-value \\
\hline Normal-weight $\dagger$ & 4.2 & - & & - & 7.8 & - & & - \\
\hline Overweight & 10.6 & 2.00 & $1.21-3.32$ & 0.007 & 9.8 & 0.90 & $0.6 \mathrm{I}-1.33$ & NS \\
\hline Obese & 16.9 & 1.91 & $1.48-2.46$ & $<0.001$ & 22.4 & 1.50 & $|.25-1.8|$ & $<0.001$ \\
\hline
\end{tabular}

Hypertension: Subjects with systolic pressure $>140 \mathrm{mmHg}$ and diastolic pressure $>90 \mathrm{mmHg}$

Diabetes: Subjects with venous gycaemia before breakfast $>126 \mathrm{~g} / \mathrm{dl}$

Normal-weight: Subjects with BMI $<25 \mathrm{Kg} / \mathrm{m}^{2}$

Overweight: Subjects with BMI $=25-29.9 \mathrm{Kg} / \mathrm{m}^{2}$

Obese: Subjects with BMI $\geq 30 \mathrm{Kg} / \mathrm{m}^{2}$

RPR: Relative Prevalence Ratio adjusted for age, gender and place of residence

† Referent group

P-value based on Pearson's chi-square test

NS $=$ Non-Significant 
There was a tendency in all age groups for more undiagnosed HT and DM in men compared to women.

\section{The relationship between overweight/obesity and undiagnosed HTIDM}

As shown in Table 4, the HT prevalence among overweight and obese participants was $10.6 \%$ and $16.9 \%$, respectively. Compared to normal-weight adults, overweight subjects with HT had an RPR of 2.00 [95\% CI:1.21-3.32], while those with obesity and HT had an RPR of 1.91 [95\% CI:1.48-2.46]; both had been adjusted for age, gender and place of residence. Finally, the DM prevalence among overweight and obese participants was $9.8 \%$ and $22.4 \%$, respectively. Compared to normalweight adults, those who had a combination of obesity and DM showed an RPR of 1.50 [95\% CI:1.25-1.81].

\section{Discussion}

We observed a high prevalence of overweight and obesity in a Mediterranean region, and this result coincides with other studies [4]. The obesity prevalence found in both men [23.8\%] and women [26.8\%] is among the highest of Europe [4.0-28.3\% in men and 6.2-36.5\% in women] [4]. The total prevalence even exceeds that of other nonEuropean countries like the United States [20.3\%] [6]. Studies done on adults in other Mediterranean areas in Spain detected similar obesity prevalences [18]. These prevalences are higher than those described for the whole of Spain [15.5\%] [3]. Therefore our results demonstrate that a geographically distributed obesity prevalence exists in Spain, which is higher in the Southeast $[5,6]$. Our study also determines the association of these overweight and obesity prevalences with undiagnosed DM and HT, which is new and different from these earlier published Spanish data.

Both overweight and obesity appears to increase with age. This may be due to people of this age living a more sedentary lifestyle. Besides, a series of physiological alterations take place with age which increase body weight [5].

The overweight prevalence generally tended to be higher in men than in women. However, the obesity prevalence tended to be higher in women than in men. This indicates that obesity prevention measures must address men and women equally.

Like other Spanish studies [19], higher overweight and obesity prevalences were noted for the rural population, although only the overweight prevalence was statistically significant. In the past, the overweight prevalence was traditionally higher in urban areas. However, the opposite trend applies nowadays [19]. This could be because subjects living in rural areas have poorer access to health care and they practice medical selfcare less.
These high overweight and obesity prevalences could be responsible for a possible epidemic of associated adverse effects $[1,3]$. Subjects with a higher BMI are at greater risk of suffering cardiovascular diseases [20-22]. An association between severe obesity and a dysfunction of the left ventricle was first observed in the mid 20's [20]. Later, clinical and necroscopic studies confirmed that cardiomyopathies were associated with obesity $[22,23]$. Echo-cardiography studies, catheterisation and necroscopic examination have revealed a relationship between obesity and certain alterations to both the heart structure and the systolic function in moderate obesity [23]. We detected that the undiagnosed HT prevalence, was statistically and significantly higher in overweight than in normal-weight subjects, and was even higher in obese subjects. Therefore, anyone who is somewhat over their ideal weight could benefit from a moderate weight loss in order to be at less risk of HT [24].

We also noted that the undiagnosed DM prevalence was statistically and significantly higher in obese subjects than in normal-weight subjects. BMI is an indicator of obesity and would be a possible indicator of the risk of DM $[25,26]$.

We also observed that the prevalence of this pathology increased significantly with age, as other authors discovered [27]. Therefore, the detection of an abnormal glucose metabolism in elderly obese subjects would help control the disease. Taking healthy lifestyle habit measures has proved more effective than pharmacological treatments to prevent the onset of DM [28]. Early prevention programmes that centre on changing lifestyle habits are very important.

This study is not without its limitations. The main limitation is the sample's lack of representativeness produced by the fact that the response rate was much more elevated in women than in men. Also, for those cases in which hyperglycaemia was absent, a diagnosis of DM was not confirmed with a second test. The Oral Glucose Tolerance Test was not done; therefore the prevalence of undiagnosed DM could be underestimated.

\section{Conclusion}

This study provides strong evidence for overweight and obesity prevalences in the general population. Besides, it demonstrates the important role that obesity plays as a main modifiable risk factor in the development of comorbidities like HT and DM and its use in early diagnoses.

\section{List of abbreviations}

BMI: Body Mass Index; CG: Capillary glycaemia; CI: Confidence Intervals; CIBER: Networked Biomedical Research Centre; DM: Diabetes Mellitus; HT: Hypertension; kg: Kil- 
ograms; RPR: Relative Prevalence Ratios; WHO: World Health Organization.

\section{Competing interests}

The authors declare that they have no competing interests.

\section{Authors' contributions}

AHM had the original idea for the work and organized the study. ESI contributed to the study design. FBM provided expert advice on study organization and contributed to the writing of the manuscript. MTMH and JVGM contributed by interpreting the results and helped to write the manuscript. NGC and MMSV did the data analysis and contributed to the writing of the paper. All the authors read and approved the final manuscript.

\section{Acknowledgements}

We are grateful to the CIBER Epidemiology and Public Health group, CB06/ 02/0045.

\section{References}

I. Ginter E, Simko V: Adult obesity at the beginning of the 2Ith century: epidemiology, pathophysiology and health risk. Bratisl Lek Listy 2008, I09:224-230.

2. Avenell A, Broom J, Brown T], Poobalan A, Aucott L, Stearns SC, Smith WC, Jung RT, Campbell MK, Grant AM: Systematic review of the long-term effects and economic consequences of treatments for obesity and implications for health improvement. Health Technol Assess 2004, 8: I- I82.

3. Aranceta J, Pérez-Rodrigo C, Serra-Majem L, Bellido D, de la Torre $M L$, Formiguera $X$, Moreno $B$ : Prevention of overweight and obesity: a Spanish approach. Public Health Nutr 2007, 10:1187-1193.

4. Berghöfer A, Pischon T, Reinhold T, Apovian CM, Sharma AM, Willich $\mathrm{SN}$ : Obesity prevalence from a European perspective: a systematic review. BMC Public Health 2008, 8:200.

5. Martínez-Ros MT, Tormo MJ, Navarro C, Chirlaque MD, PérezFlores D: Extremely high prevalence of overweight and obesity in Murcia, a Mediterranean region in south-east Spain. Int J Obes Relat Metab Disord 2001, 25:1372-1380.

6. Gabriel R, Alonso M, Segura A, Tormo MJ, Artigao LM, Banegas JR, Brotons C, Elosua R, Fernández-Cruz A, Muñiz J, Reviriego B, Rigo F, ERICE Cooperative Group: Prevalence, geographic distribution and geographic variability of major cardiovascular risk factors in Spain. Pooled analysis of data from population-based epidemiological studies: the ERICE Study. Rev Esp Cardiol 2008, 61:1030-1040.

7. Pischon T, Boening H, Hoffmann K, Bergmann M, Schulze MB, Overvad $\mathrm{K}$ : General and abdominal adiposity and risk of death in Europe. N Engl J Med 2008, 359:2105-2I 20.

8. World Health Organization: Obesity: preventing and managing the golobal epdemic Geneva, WHO; 1997.

9. Allman-Farinelli MA, Chey T, Bauman AE, Gill T, James WP: Age, period and birth cohort effects on prevalence of overweight and obesity in Australian adults from 1990 to 2000. Eur J Clin Nutr 2007, 62:898-907.

10. Schröder $\mathrm{H}$ : Protective mechanisms of the Mediterranean diet in obesity and type 2 diabetes. J Nutr Biochem 2007, I 8:149-160.

II. Gikas A, Sotiropoulos A, Panagiotakos D, Peppas T, Skliros E, Pappas $S$ : Prevalence, and associated risk factors, of self-reported diabetes mellitus in a sample of adult urban population in Greece: MEDICAL Exit Poll Research in Salamis [MEDICAL EXPRESS 2002]. BMC Public Health 2004, 4:2.

12. Davy KP, Hall JE: Obesity and hypertension: two epidemics or one? Am J Physiol Regul Integr Comp Physiol 2004, 286:803-8I3.

13. Wee CC, Phillips RS, Legedza AT, Davis RB, Soukup JR, Colditz GA, Hamel MB: Health care expenditures associated with over- weight and obesity among US adults: importance of age and race. Am J Public Health 2005, 95: I59-165.

14. Madden SG, Loeb SJ, Smith CA: An integrative literature review of lifestyle interventions for the prevention of type II diabetes mellitus. J Clin Nurs 2008, I 7:2243-2256.

15. Census. Instituto Nacional de Estadística [INE] [http:// www.ine.es/]

16. American Diabetes Association [ADA] [http://www.diabe tes.org/about-diabetes.jsp]

17. Jenicek M: Epidemiology, evidenced-based medicine, and evidence-based public health. J Epidemiol 1997, 7:187-197.

18. Vioque J, Vicente MC: The prevalence of obesity in Orihuela, Alicante, Spain. A comparison with the data from the National Health Care Survey in Spain. Med Clin 1994, 1 03:636.

19. Cea-Calvo L, Moreno B, Monereo S, Gil-Guillén V, Lozano JV, MartíCanales JC, Llisterri JL, Aznar J, González-Esteban J, Redón J, PREVICTUS Study: Prevalence and related factors of overweight and obesity in Spanish population aged 60 years-old or older. The PREV-ICTUS study. Med Clin 2008, I 3 I:205- I I0.

20. Silventoinen K, Magnusson PK, Neovius M, Sundström J, Batty GD, Tynelius P, Rasmussen F: Does Obesity Modify the Effect of Blood Pressure on the Risk of Cardiovascular Disease?. A Population-Based Cohort Study of More Than One Million Swedish Men. Circulation 2008, I I 8: I637-I642.

21. Gudelj-Radi J, Davidovi D, Avramovi D, Backovi D, Jorga J: Factors mediating the depression in the adult obese outpatients. Srp Arh Celok Lek 2007, I 35:6I-66.

22. Shoelson SE, Herrero L, Naaz A: Obesity, inflammation, and insulin resistance. Gastroenterology 2007, I32:2 I69-2 I80.

23. Pascual M, Pascual DA, Soria F, Vicente T, Hernández AM, Tébar FJ, Valdés $M$ : Effects of isolated obesity on systolic and diastolic left ventricular function. Heart 2003, 89: I I52-I I 56.

24. De Luis DA, Aller R, Izaola O, Gonzalez Sagrado M, Conde R, Perez Castrillon JL: Effects of lifestyle modification on adipocytokine levels in obese patients. Eur Rev Med Pharmacol Sci 2008, I 2:33-39.

25. Meisinger C, Döring A, Thorand B, Heier M, Löwel H: Body fat distribution and risk of type 2 diabetes in the general population: are there differences between men and women? The MONICA/KORA Augsburg cohort study. Am J Clin Nutr 2006, 84:483-489.

26. Vazquez G, Duval S, Jacobs DR Jr, Silventoinen K: Comparison of body mass index, waist circumference, and waist/hip ratio in predicting incident diabetes: a meta-analysis. Epidemiol Rev 2007, 29: II5-128.

27. Crandall J, Schade D, Ma Y, Fujimoto WY, Barrett-Connor E, Fowler $S$, Dagogo-jack S, Andres R: The influence of age on the effects of lifestyle modification and metformin in prevention of diabetes. J Gerontol A Biol Sci Med Sci 2006, 6 I: 1075-108I.

28. Waugh N, Scotland G, McNamee P, Gillett M, Brennan A, Goyder E, Williams R, John A: Screening for type 2 diabetes: literature review and economic modelling. Health Technol Assess 2007, I I: I- 125 .

Publish with Biomed Central and every scientist can read your work free of charge

"BioMed Central will be the most significant development for disseminating the results of biomedical research in our lifetime. "

Sir Paul Nurse, Cancer Research UK

Your research papers will be:

- available free of charge to the entire biomedical community

- peer reviewed and published immediately upon acceptance

- cited in PubMed and archived on PubMed Central

- yours - you keep the copyright 